\title{
Liquid phase dehydration of methyl phenylcarbinol to styrene
}

\author{
(C) Tulkinbek S. Sitmuratov, ${ }^{+}$Lyubov A. Petukhova, and Alexandr A. Petukhov* ${ }^{+}$ \\ Department of Synthetic Rubber Technology. Kazan National Research Technological University. \\ K. Marx St., 68. Kazan, 420015. Tatarstan Republic. Russia.E-mail:Petukhov-AA@yandex.ru
}

\begin{abstract}
*Supervising author; ${ }^{+}$Corresponding author
Keywords: co-production of styrene and propylene oxide, catalytic liquid-phase method of dehydration, methylphenylcarbinol, heavy residue, conversion, styrene, acetophenone, comparison of catalysts activity, styrene formation selectivity.
\end{abstract}

\section{The industrial styrene production by the method of vapor-phase methylphenylcarbinol (MPhC)} dehydration was introduced for the first time in our country within the joint propylene oxide and styrene production consisting OAO «Nizhnekamskneftekhim» facility.

This process makes it economically feasible to obtain a combined product - propylene oxide and styrene. However, continuous process exploitation at the OAO «Nizhnekamskneftekhim» facility allowed revealing a number of significant faults caused by economic and environmental factors toughening. First of all it is high energy consumption due to high process temperature and high water steam consumption for steam dilution, which affects the increase in the cost of production.

In almost all technological scheme areas of this production, high boiling by-products, so-called high boiling components, are formed.

One of these problem solution versions is the transfer of production to a new technology of styrene production by MPhC dehydration, which is carried out in the liquid phase at lower temperatures (up to 190 ${ }^{\circ} \mathrm{C}$ ) using new homogeneous highly selective catalysts that exclude the by-products formation, including highboiling components.

The principal advantage of this technology is to reduce the cost of marketable styrene by reducing energy costs (heat, recycled water, water vapor, fuel gas, electricity), reducing the metal consumption of the technological scheme and increasing styrene production by reducing the amount of waste.

The comparative tests results with three samples of homogeneous catalysts activity in the MPhC dehydration into styrene process are presented in the work.

The tests were carried out under conditions of periodically and continuously operating laboratory installations made of glass, equipped with dosing, condensation, separation and collection systems for reaction products. Quantitative composition of reaction products is identified by chromatography methods.

As a result of the conducted tests, in the presence of the used catalysts, the process control modes were selected, and the installations efficiency was checked.

\section{References}

[1] P.A. Kirpichnikov, V.V. Beresnev, L.M. Popova. The album of the main synthetic rubber industries technological schemes. Leningrad: Chemistry. 1986. 224p. (russian)

[2] Patent RU 2104991 of PJSC "Nizhnekamskneftekhim". 1998. A.A. Petukhov, V.A. Komarov, V.A. Belokurov, I.M. Vasiliev, A.P. Vorozheikin, V.P. Zuev and others. Styrene production method. (russian)

[3] Patent RU 2083543 of PJSC "Nizhnekamskneftekhim". 1995. V.A. Komarov, A.A. Petukhov, G.Z. Sakhapov, V.A. Belokurov, I.M. Vasiliev, V.P. Zuev, G.N. Melnikov. Styrene production method. (russian)

[4] Pat. RU 20000104167 Styrene producing method by dehydration of methylphenylcarbinol-containing raw materials in the acid catalyst presence. A.A. Petukhov, B.R. Serebryakov, V.A. Komarov. 02.21.00. (russian)

[5] T.S. Sitmuratov, L.A. Petukhova, I.I. Bakhtinova, A.A. Petukhov. Comparison of the homogeneous catalysts activity during the liquid phase methylphenylcarbinol dehydration to styrene. International scientific conference materials "Innovative solutions of engineering and technological problems of modern production", "Scientific problems and prospects for the oil and gas industry development" Uzbekistan. Bukhara city. 2019. Vol.1. Section 4. P.381-384. 
[6] T.S. Sitmuratov, L.A. Petukhova, I.I. Bakhtinova, and A.A. Petukhov. Catalytic decomposition of highboiling residue fractions formed during the styrene and propylene oxide producing process. Butlerov Communications. 2018. Vol.56. No.10. P.118-122. DOI: 10.37952/ROI-jbc-02/18-56-10-118

[7] T.S. Sitmuratov, I.I. Bakhtinova, M.I. Khabibrakhmanov, A. A. Petukhov. The catalyst effect on the styrene yield in the liquid-phase process of methylphenylcarbinol dehydration. Regional youth and student festival Human. «Citizen. Scientist (ChSU-2019)». Cheboksary. 2019. (russian)

[8] T.S. Sitmuratov, I.I. Bakhtinova, M.I. Khabibrakhmanov, A. A. Petukhov. The catalyst nature influence on the formation of heavy products in the styrene producing process. Regional festival of student youth «Human. Citizen. Scientist (ChSU-2019)». Cheboksary. 2019. (russian) 